\title{
Mirogabalin and emerging therapies for diabetic neuropathy
}

This article was published in the following Dove Press journal: Journal of Pain Research

\author{
Saad Javed ${ }^{1,2}$ \\ Uazman Alam ${ }^{3-5}$ \\ Rayaz A Malik $1,2,6$
}

'Manchester Academic Health Sciences Centre, University of Manchester, Manchester, UK; ${ }^{2}$ Manchester University Hospital, Manchester, UK; ${ }^{3}$ Diabetes and Endocrinology Research, Department of Eye and Vision Sciences and Pain Research Institute, Institute of Ageing and Chronic Disease, University of Liverpool and Aintree University Hospital NHS Foundation Trust, Liverpool, UK; ${ }^{4}$ Department of Diabetes and Endocrinology, Royal Liverpool and Broadgreen University NHS Hospital Trust, Liverpool, UK; ${ }^{5}$ Division of Endocrinology, Diabetes and Gastroenterology, University of Manchester, Manchester, UK; ${ }^{6}$ Department of Medicine, Weill Cornell Medicine-Qatar, Doha, Qatar

Correspondence: Rayaz A Malik Weill Cornell Medicine-Qatar, Qatar Foundation, Education City, PO Box 24144, Doha, Qatar

Tel +97444928256

Email ram2045@qatar-med.cornell.edu

\begin{abstract}
There are currently no approved disease-modifying therapies for diabetic neuropathy, and there are only 3 US Food and Drug Administration-approved therapies (pregabalin, duloxetine, and tapentadol) for painful diabetic neuropathy. They each have moderate efficacy with adverse effects limiting optimal dose titration. There is a considerable need for new therapies for the management of painful diabetic neuropathy. We reviewed the potential role of mirogabalin, which like gabapentin and pregabalin modulates the alpha-2/delta-1 subunit of the voltage-gated calcium channel, allowing the influx of calcium and release of neurotransmitters at the synaptic cleft in the central nervous system and spinal cord. It has shown efficacy and good tolerability in a Phase II study in diabetic painful neuropathy and based on the results of two Phase III clinical trials in diabetic painful neuropathy and post-herpetic neuralgia, Daiichi Sankyo submitted a marketing application for neuropathic pain in Japan in February 2018. We have also reviewed potential new therapies, currently in Phase II clinical trials that may modify disease and/or relieve neuropathic pain through novel modes of action.
\end{abstract}

Keywords: diabetic neuropathy, painful diabetic neuropathy, treatment, mirogabalin

\section{Introduction}

Diabetic peripheral neuropathy (DPN) is among the most frequently encountered longterm complications of diabetes and has a prevalence of at least $50 \% .^{1,2}$ It is characterized by small and large fiber dysfunction and damage as a consequence of metabolic and vascular risk factors. DPN remains an unmet need for both patients and physicians and is a primary driver of physical and psychological comorbidity. Indeed, both quality of life and economic burden associated with DPN are significant and moreover, it is strongly associated with mortality. ${ }^{3-5}$ Several phenotypic variants of diabetic neuropathy have been recognized, but the most common is distal symmetrical polyneuropathy, an ascending neuropathy occurring in a glove and stocking distribution accounting for $\sim 75 \%$ of diabetic neuropathies. ${ }^{6}$ The symptoms in DPN are often related to small nerve fiber dysfunction and manifest as pain and dysesthesia, classically described as an unpleasant "burning", "shooting", "prickly", and "excruciating" pain, typical of neuropathic pain. ${ }^{7,8}$ Painful DPN is particularly difficult to manage and although a number of agents are available, optimal pain control is inadequate. ${ }^{5,9}$

\section{Current therapies}

There are no FDA-approved disease-modifying therapies for DPN. Optimizing glycemic control remains the most broadly accepted approach to prevent the progression 
of neuropathy with moderate benefit in patients with Type 1 diabetes, ${ }^{10}$ but with limited benefit in Type 2 diabetes. ${ }^{11}$ Simultaneous pancreas and kidney transplantation restores normoglycemia and renal function and may reverse DPN. ${ }^{12}$

\section{Controlling pain in diabetic neuropathy}

Neuropathic pain is a debilitating feature of DPN resulting in significant morbidity. ${ }^{5,13}$ Although tight glycemic control may prevent the progression of diabetic neuropathy, there is a paucity of data suggesting that improved glycemic control improves pain in DPN. ${ }^{14}$ Moderate improvements in pain are considered to be $\sim 30 \%-50 \%$ pain relief, whereas $>50 \%$ pain relief is considered a good outcome. ${ }^{15}$ Unfortunately, painful DPN responds poorly to conventional analgesics, but tend to be frequently used especially in primary care settings. ${ }^{16}$ Guidelines do not recommend nonsteroidal anti-inflammatories due to their lack of efficacy and propensity to deteriorate renal function. ${ }^{9}$ Currently, five professional organizations have produced expert guidance on the management of painful diabetic neuropathy. ${ }^{8,17-21}$ Medications recommended include tricyclic antidepressants (TCAs), serotonin-norepinephrine reuptake inhibitors (SNRIs), or $\gamma$-aminobutyric acid (GABA) analogs (gabapentin or pregabalin) as first-line agents followed by opioids and topical treatments. The only two medications with both FDA and European Medicines Agency (EMA) approval for the treatment of painful DPN are pregabalin and duloxetine. Recently, the COMBO-DN study has shown the effectiveness of a combination of duloxetine and pregabalin in painful DPN. ${ }^{22}$

\section{Tricyclic antidepressants}

Developed initially for depression, TCAs are commonly used as analgesics for neuropathic pain in contemporary clinical practice. The exact mechanism promoting analgesia in painful DPN is still not precisely known, but they are known to act through a number of pathways, with antagonistic actions at the $N$-methyl-D-aspartate, 5-HT, histamine, muscarinic, and $\alpha$-adrenergic receptors while also blocking the reuptake of noradrenaline and serotonin from synaptic clefts ${ }^{23}$ as well as indirect modulation of the opioid system in the brain. ${ }^{24-26}$ The use of TCAs is limited by their adverse effect profile. ${ }^{27}$

\section{Serotonin-norepinephrine reuptake inhibitors}

The SNRIs exert their analgesic effects by altering the balance of neurotransmitters centrally and through stimulation of descending inhibitory pathways by selectively antagonizing the effects of both serotonin and norepinephrine. ${ }^{28}$
Duloxetine was the first agent to be approved by the FDA for the treatment of diabetic painful neuropathy based on data from several large randomized controlled trials. ${ }^{29-33}$ Goldstein et al demonstrated that doses of 60 and $120 \mathrm{mg}$ of duloxetine were associated with an improvement in average daily pain scores in a randomized, placebo-controlled trial in 457 patients. ${ }^{31}$ More recently, Lunn et al conducted a Cochrane review, analyzing data from eight different studies $(n=2,728)$, comparing duloxetine to placebo. ${ }^{29}$ They reported that doses of 60 and $120 \mathrm{mg}$ of duloxetine were associated with a significant improvement in neuropathic pain in DPN. The adverse effect profile of duloxetine is more favorable compared with TCAs, with fewer anti-muscarinic adverse effects. ${ }^{34,35}$ Patients treated with duloxetine were found to have slight weight gain and raised fasting glucose levels, although to a lesser extent than with pregabalin. ${ }^{36}$ Duloxetine is considered to be more cost-effective than pregabalin and was approved for the treatment of diabetic painful neuropathy by National Institute for Clinical Excellence.

\section{$\mathrm{GABA}_{\mathrm{A}} \alpha_{2} \delta$ subunit}

The $\alpha_{2} \delta$ subunit $\left(\alpha_{2} \delta-1\right.$ and $\alpha_{2} \delta$-2) of voltage-sensitive calcium channels in the central nervous system (CNS) has been utilized as the molecular target for pain relief in neuropathic pain. The FDA and EMA have approved pregabalin as first-line treatment for painful DPN. ${ }^{19,37,38}$ Both pregabalin and gabapentin act as a nonselective ligand at the $\alpha 2 \delta-1$ and $\alpha 2 \delta-2$ subunits. The structure of these channels is composed of a central pore-forming alpha-1 subunit, a disulfide-linked glycoprotein consisting of $\alpha 2 \delta$ subunits and intracellular beta subunits. Enhanced understanding of the $\alpha 2 \delta$ subunits has suggested that $\alpha 2 \delta-1$ and $\alpha 2 \delta-2$ may in fact have different clinical effects. ${ }^{39,40}$ Binding to $\alpha_{2} \delta-1$ may contribute to analgesic effects, whereas binding to $\alpha_{2} \delta-2$ appears to contribute to undesirable CNS effects such as somnolence. ${ }^{37,41,42}$ Additional experimental studies have shown that $\mathrm{GABA}_{\mathrm{A}}$ receptors containing $\alpha 2 \delta-2$ and $\alpha 2 \delta-3$ subunits are crucial components of spinal pain control. Defining the precise role of $\mathrm{GABA}_{\mathrm{A}}$ receptor subtypes remains a key area for therapeutic advancement to ensure that novel GABA modulators are developed as a potential new therapeutic area for chronic neuropathic pain. ${ }^{39,40}$ More recently, it has been suggested that $\mathrm{GABA}_{\mathrm{A}} \alpha 5$ receptors play a role in the loss of GABAergic inhibition and contribute to long-lasting secondary allodynia and hyperalgesia, ${ }^{43}$ and antagonism of GABA $_{A} \alpha 2 \delta-5$ leads to reversal of impaired rate-dependent depression of the Hofmann reflex, a potential biomarker for spinally mediated pain secondary to loss of GABAergic 
inhibition in diabetes. ${ }^{44,45}$ AZD7325 is a novel partial $\alpha 2 \delta-2,3$ subtype-selective $\mathrm{GABA}_{\mathrm{A}}$ receptor modulator with minimal in vitro efficacy at the $\alpha 2 \delta-1$ and $\alpha 2 \delta$ - 5 receptor subtypes and produces anxiolytic effects in humans associated with selective $\mathrm{GABA}_{\mathrm{A}} \alpha 2 \delta-2,3$ agonism. ${ }^{46}$ There was increased expression of $\mathrm{GABA}_{\mathrm{A}} \alpha 2 \delta-1$ mRNA and $\alpha 2 \delta-1$ protein in the dorsal root ganglion and dorsal horn of rat models of neuropathic pain. ${ }^{47}$ Transgenic mice with elevated neuronal expression of the $\alpha 2 \delta-1$ subunit exhibited hypersensitivity to both tactile allodynia and thermal hyperalgesia and electrophysiological hyperexcitability in the dorsal root ganglion and spinal cord. ${ }^{48}$ Gabapentin blocked voltage-gated calcium channel currents in a concentration-dependent manner in these transgenic mice. ${ }^{48}$ The role of $\mathrm{GABA}_{\mathrm{A}}$ subtypes in promoting analgesia is complex and requires further study.

\section{Gabapentin}

Widely prescribed for diabetic neuropathy, gabapentin inhibits the presynaptic calcium channel at the $\alpha 2 \delta$ ligand. ${ }^{49}$ Backonja et al randomized patients in a ratio of $1: 1$ to receive either gabapentin or placebo and reported a number needed to treat (NNT) of 3.7 to achieve $50 \%$ pain relief after 8 weeks of treatment. ${ }^{50}$ Since then several studies have confirmed the efficacy of gabapentin for neuropathic pain. ${ }^{51-57}$ Several systematic reviews have found a significant analgesic effect of gabapentin in neuropathic pain ${ }^{27,58}$ and a Cochrane Collaboration review on gabapentin reported an NNT of 5.9 for the relief of neuropathic pain. ${ }^{59}$ Rudroju et al compared the efficacy and safety of a number of drugs in painful DPN and concluded that gabapentin offered the most favorable balance of safety and efficacy. ${ }^{27}$

\section{Pregabalin}

Pregabalin has higher reported potency due to higher absorption and affinity for the $\alpha 2 \delta 1$ subunit. The efficacy of pregabalin in painful diabetic neuropathy has been established in four double-blind placebo-controlled trials, ${ }^{60-63}$ and a recent meta-analysis found that pregabalin was the most efficacious agent for the management of painful DPN when patients were asked to grade their level of pain on a visual analog scale. ${ }^{64}$ It exhibits a dose-dependent response, with $600 \mathrm{mg}$ being associated with the greatest analgesic effect, improved mood, and less sleep interference. Sicras et al also reported that pregabalin was associated with reduced healthcare costs in a cost-comparative analysis of patients treated with pregabalin and gabapentin. ${ }^{65}$ Weight gain can be an issue with pregabalin, and in a pooled analysis of 41 trials $(n=3,187)$ while the majority of patients treated with pregabalin (150-600 mg/day) for 1 year maintained weight within $\pm 7 \%$ of their baseline weight, one in six patients gained $\geq 7 \%$ weight from baseline within 2-12 months of commencing treatment. ${ }^{36}$ Patients should also be warned against abrupt discontinuation of pregabalin, as this has been associated with encephalopathy and cerebral edema, and there is the issue of recreational abuse amongst illicit drug users. ${ }^{66,67}$

\section{Combination therapy}

The COMBO-DN study was designed to compare the efficacy and tolerability of high-dose monotherapy (duloxetine $120 \mathrm{mg}$ daily or pregabalin $600 \mathrm{mg}$ daily) to standard dose combination therapy (duloxetine $60 \mathrm{mg}$ and pregabalin 300 mg daily) in patients with painful DPN who were resistant to standard dose monotherapy. ${ }^{22}$ There was no significant difference between standard dose combination therapy and high-dose monotherapy. ${ }^{22}$ In a secondary analysis, duloxetine $60 \mathrm{mg} /$ day was superior to pregabalin $300 \mathrm{mg} /$ day in the initial 8-week run-in phase, and this remains the only headto-head trial of pregabalin and duloxetine.

\section{Other anticonvulsants}

Other anticonvulsants such as lamotrigine and topiramate have been studied in painful diabetic neuropathy. A Cochrane review analyzed four trials of lamotrigine in painful DPN and found no evidence of its efficacy. ${ }^{68,69}$ Trials evaluating topiramate have reported similar conflicting findings. ${ }^{64,70,71}$ Although Raskin et al reported that topiramate was efficacious in the management of painful diabetic neuropathy, Thienel et al reported that a number of smaller studies had not shown any benefit. ${ }^{70,71}$ It is evident that achieving adequate pain relief in painful DPN remains difficult for many patients and adequate analgesia may require combination therapy. The need for new more effective agents is apparent.

\section{The case for mirogabalin}

Mirogabalin and pregabalin were recently compared in partial sciatic nerve ligation and streptozotocin-induced diabetes. ${ }^{47}$ Mirogabalin showed more selective binding affinity for the human and rat $\alpha_{2} \delta$ subunits, with a slower dissociation for the $\alpha_{2} \delta$-1 subunit compared with the $\alpha_{2} \delta$-2 subunit and hence potent analgesia with less CNS side effects.

\section{Pharmacokinetics}

The pharmacokinetics of mirogabalin has been studied extensively in healthy subjects with doses ranging from 3 to $75 \mathrm{mg}$ (data on file, Daiichi Sankyo). ${ }^{72}$ Following oral administration, maximum plasma concentration of mirogabalin is 
achieved at $\sim 1$ hour. $^{72}$ The area under the plasma concentration-time curve and maximum plasma concentration are proportional with higher doses. ${ }^{72}$ The plasma protein binding of mirogabalin is relatively low at $\sim 25 \%$ in humans. ${ }^{72}$ The drug is largely renally excreted and undergoes minimal in vivo metabolism. ${ }^{72} \mathrm{~A}$ multicenter open-label study assessed the pharmacokinetics and safety of a single dose of $5 \mathrm{mg}$ mirogabalin in 30 participants with normal, mild, moderate, or severe renal impairment. ${ }^{73}$ The plasma concentrationtime curve increased with severity of renal impairment. ${ }^{73} \mathrm{~A}$ statistical model detailing the population pharmacokinetics of mirogabalin in relation to varying degrees of renal impairment has been developed and identified an effect on renal and nonrenal clearances of mirogabalin. ${ }^{72}$ The simulation suggested reducing the dose of mirogabalin by $50 \%$ in people with moderate renal impairment and by $75 \%$ in people with severe renal impairment. ${ }^{72} \mathrm{~A}$ recent randomized, placebocontrolled, double-blind, sequential, ascending-dose study evaluated single (10-40 mg) and repeated (10, $15 \mathrm{mg}$ twice a day) doses of mirogabalin in Japanese, Korean, Chinese and White subjects and demonstrated comparable pharmacokinetic parameters. ${ }^{74}$

\section{Clinical studies}

Vinik et al conducted a multicenter, randomized, doubleblind, placebo- and active comparator-controlled, proof-ofconcept Phase II study. ${ }^{42}$ In this study, adults with diabetic painful neuropathy of 6 months or greater were randomized $(2: 1: 1: 1: 1: 1: 1)$ to receive placebo, increasing doses of mirogabalin $(5,10,15,20$, and $30 \mathrm{mg}$ daily), and pregabalin 300 mg daily for 5 weeks. ${ }^{42}$ The severity of pain was measured over 5 weeks with a meaningful effect described as a 1-point or greater change in average daily pain score (rated on a numerical scale of $0-10$ ). A dose of $30 \mathrm{mg}$ mirogabalin caused a reduction in average daily pain scores of 1 or greater, whereas 15 and $20 \mathrm{mg}$ doses caused a statistically significant reduction in pain scores; this was not considered to be clinically meaningful. Median time to meaningful pain relief was $30,16,20$, and 16 days in the mirogabalin 10, 15, 20, and 30 $\mathrm{mg}$ /day groups, compared with 36 days in the placebo group ( $P<0.05$ for all comparisons $)$.

There were statistically significant differences in the change in the average daily pain score between pregabalin $300 \mathrm{mg}$ and mirogabalin 15 and $30 \mathrm{mg}$. However, subjects in the pregabalin arm received $300 \mathrm{mg}$ in divided doses and it remains unknown whether higher single doses would have affected efficacy. Second, the placebo response rate was higher than expected in this study as Freeman et al previously showed a placebo response of -1.47 , whereas in the present study, it was $-1.86 .^{75}$ This single study suggests that mirogabalin may have a role in the management of painful diabetic neuropathy. However, the unique design of the trial necessitates caution when comparing these data with other published trials.

In addition to efficacy, this Phase II trial assessed the safety of mirogabalin using adverse event (AE) data, clinical laboratory tests, and electrocardiograms. Most frequent AEs $(\mathrm{n}=277)$ were mild to moderate dizziness $(9.4 \%)$, somnolence $(6.1 \%)$, and headache $(6.1 \%)$; otherwise, mirogabalin was well tolerated. Hutmacher et al carried out exposure-response modeling for mirogabalin with respect to pain scores and adverse effects and showed that the incidence of dizziness and somnolence decreased over time and twice-daily dosing of mirogabalin was predicted to yield a lower incidence of dizziness compared with once-daily dosing. ${ }^{76}$ Taken together, these findings suggest that the doses of mirogabalin can be titrated to achieve equivalent analgesic effect to pregabalin but with less adverse effects, particularly dizziness. ${ }^{76}$ While, mirogabalin was well tolerated in Japanese subjects with normal and mild to severe renal impairment, dizziness, somnolence, and vomiting were reported with greater frequency in those with end-stage renal disease. It is therefore likely that the dose of mirogabalin will need dose adjustment in patients with moderate to severe renal impairment. However, of note only $5 \mathrm{mg}$ of mirogabalin was used, and as reported previously this dose is unlikely to demonstrate a clinically meaningful analgesic effect in painful DPN. ${ }^{42}$

\section{Efficacy of mirogabalin compared with pregabalin, gabapentin, and duloxetine}

In the absence of direct head-to-head trials and given the paucity of efficacy data on mirogabalin, any comparisons between agents must be made with caution. Vinik et al reported that the percentage of subjects who reported $\mathrm{a} \geq 50 \%$ reduction in average daily pain scores were $20 \%, 29 \%, 39 \%$, $43 \%$, and $44 \%$ after 5 weeks for $5,10,15,20$, and $30 \mathrm{mg}$ of mirogabalin, respectively. ${ }^{42}$ In a Cochrane review by Moore et al, a $\geq 50 \%$ reduction in average daily pain scores was achieved in $41 \%$ of patients receiving $600 \mathrm{mg}$ of pregabalin. ${ }^{77}$ For gabapentin ${ }^{78}$ and duloxetine, ${ }^{29} \mathrm{a} \geq 50 \%$ reduction in pain was found in $38 \%$ and $40 \%$, respectively (Table 1 ).

\section{AEs of mirogabalin compared with pregabalin, gabapentin, and duloxetine}

The frequency of CNS adverse effects was $14 \%$ in the mirogabalin group compared with $12 \%$ in the pregabalin group (39). Seven percent of patients in the mirogabalin group 
were unable to continue with treatment compared with $4 \%$ in the placebo group. This compares favorably to duloxetine, where a Cochrane review of 18 trials $(n=6,407)$ reported that $\sim 12.5 \%$ of patients had to discontinue duloxetine due to adverse effects. ${ }^{29} \mathrm{~A}$ similar $12 \%$ rate of discontinuation due to AEs has been reported for gabapentin. ${ }^{59}$ A Cochrane review of pregabalin reported treatment discontinuation due to AEs in $18 \%-28 \%$ of subjects, though most trials utilized $600 \mathrm{mg}$ of pregabalin. ${ }^{42,77}$

Mirogabalin has equivalent efficacy but may be a more tolerable therapeutic option for painful diabetic neuropathy based on a comparison of efficacy and AEs (Table 1).

\section{Novel therapies in DPN}

There has been increasing interest in agents that target the pathophysiology of diabetic neuropathy. Vincent et al recently reviewed a number of cellular targets that could be used to develop novel therapies for DPN. ${ }^{8,79}$ Manipulation of the temperature-sensitive transient receptor potential (TRP) channel on nociceptive neurons has been proposed as an attractive strategy in targeting the pain pathway, especially since TRPV1 desensitization by topical agonists such as capsaicin has been used for painful DPN. ${ }^{80}$ VEGF-derived peptides may also be utilized as a pathogenetic therapy in diabetic neuropathy. ${ }^{81,82}$ Ropper et al investigated VEGF for the treatment of diabetic neuropathy in a double-blind randomized trial but failed to show efficacy. ${ }^{82}$ The angiotensin II type 2 receptor (AT2R) axis plays a substantial role in promoting nociceptive signaling by stimulating hyperexcitability and persistent ectopic firing of first-order sensory neurons. ${ }^{83}$ Though AT2R antagonists have been long developed, they are now being repositioned as treatments for painful neuropathy. ${ }^{84}$ In a Phase IIa study, Rice et al demonstrated the efficacy and safety of EMA401, a small molecular AT2R antagonist, in a cohort of 182 patients with postherpetic neuralgia. ${ }^{85}$ Clinical trials are currently suspended following acquisition of the agent by Novartis. ${ }^{84,86}$

Table I Comparison of percentage with $\geq 50 \%$ reduction in average daily pain scores, number needed to treat (NNT), and percentage of patients who withdrew due to adverse events (AEs) comparing mirogabalin, pregabalin, gabapentin, and duloxetine

\begin{tabular}{llll}
\hline Drug & $\begin{array}{l}\mathbf{2 5 0} \% \text { pain } \\
\text { relief }\end{array}$ & NNT & $\begin{array}{l}\text { \% Withdrawal } \\
\text { AE }\end{array}$ \\
\hline Mirogabalin $30 \mathrm{mg}$ & $44 \%$ & 5.0 & $7 \%$ \\
Pregabalin $600 \mathrm{mg}$ & $41 \%$ & 5.0 & $18 \%-28 \%$ \\
Gabapentin $\geq 1,200 \mathrm{mg}$ & $38 \%$ & 5.9 & $12 \%$ \\
Duloxetine $60 \mathrm{mg}$ & $40 \%$ & 5.0 & $12.5 \%$ \\
\hline
\end{tabular}

Mutations in the Nav1.7 sodium channel have recently been described in a significant proportion of patients with painful diabetic neuropathy. ${ }^{87}$ Numerous Nav1.7 antagonists are currently in development. Xenon402, a novel Nav1.7 blocker, was found to be effective in erythromelalgia and it has been suggested that Nav1.7 blockers may be useful in other types of neuropathic pain. ${ }^{88,89}$

Intrathecal drugs can be delivered at high concentration into the cerebrospinal fluid, limiting systemic adverse effects. ${ }^{90}$ Whilst intrathecal morphine and ziconotide are approved for intractable pain, ${ }^{91}$ they have not been evaluated in DPN. Moreover, one should be cautious in the implantation of intrathecal delivery systems in relation to myelitis and arachnoiditis ${ }^{92}$ and impaired wound healing in patients with diabetes.

Produced by cells under stress, erythropoietin (EPO) is known to antagonize the production of proinflammatory molecules and as a consequence promotes tissue regeneration. ${ }^{93,94}$ In experimental models, EPO is known to ameliorate DPN, but its use in humans is precluded by tendency to cause thrombosis. ARA290 is a nonhematopoietic peptide synthesized from EPO, which selectively targets the innate repair receptor, downregulating inflammation, without the procoagulant effects of EPO. ${ }^{95}$ In a recent Phase II trial of ARA290 in patients with painful DPN, patients receiving ARA290 for 28 days reported a significant improvement in neuropathic symptoms compared with placebo. ${ }^{95,96} \mathrm{~A}$ recent analysis of patients with sarcoidosis and small fiber neuropathy treated with ARA290 using corneal confocal microscopy demonstrated small nerve fiber repair, suggesting a pathogenetic role for ARA290. ${ }^{97}$ Moreover, Zhang et al demonstrated that ARA290 can specifically inhibit TRPV1 channel activity and relieve capsaicin-induced hypersensitivity, indicating a dual basis for the efficacy of this drug in diabetic neuropathy. ${ }^{98}$

\section{Conclusion}

The rising global burden of diabetes is spurring an increase in the prevalence of diabetic neuropathy and neuropathic pain. At present, there are no FDA-approved pathogenetic therapies for DPN and the efficacy of treatments for painful DPN is limited. Therefore, there is a major need for the development of novel disease-modifying and analgesic therapies for diabetic neuropathy. The promising data on mirogabalin suggests that it may soon be the fourth drug to receive market approval for neuropathic pain.

\section{Disclosure}

U Alam has received honoraria for speaking at educational meetings organized by Pfizer. RA Malik has received hono- 
raria for speaking at educational meetings organized by Pfizer and Novo Nordisk. The authors report no other conflicts of interest in this work.

\section{References}

1. Albers JW, Pop-Busui R. Diabetic neuropathy: mechanisms, emerging treatments, and subtypes. Curr Neurol Neurosci Rep. 2014; 14(8):473

2. Young MJ, Boulton AJ, MacLeod AF, Williams DR, Sonksen PH. A multicentre study of the prevalence of diabetic peripheral neuropathy in the United Kingdom hospital clinic population. Diabetologia. 1993;36(2): $150-154$.

3. Oliveira AF, Valente JG, Leite Ida C, Schramm JM, Azevedo AS, Gadelha AM. Global burden of disease attributable to diabetes mellitus in Brazil. Cad Saude Publica. 2009;25(6):1234-1244.

4. Vinik A, Emir B, Cheung R, Whalen E. Relationship between pain relief and improvements in patient function/quality of life in patients with painful diabetic peripheral neuropathy or postherpetic neuralgia treated with pregabalin. Clin Ther. 2013;35(5):612-623.

5. Gore M, Brandenburg NA, Dukes E, Hoffman DL, Tai KS, Stacey B. Pain severity in diabetic peripheral neuropathy is associated with patient functioning, symptom levels of anxiety and depression, and sleep. J Pain Symptom Manage. 2005;30(4):374-385.

6. Dyck PJ, Albers JW, Andersen H, et al. Diabetic polyneuropathies: update on research definition, diagnostic criteria and estimation of severity. Diabetes Metab Res Rev. 2011;27(7):620-628.

7. Freeman R, Baron R, Bouhassira D, Cabrera J, Emir B. Sensory profiles of patients with neuropathic pain based on the neuropathic pain symptoms and signs. Pain. 2014;155(2):367-376.

8. Iqbal Z, Azmi S, Yadav R, et al. Diabetic peripheral neuropathy: epidemiology, diagnosis, and pharmacotherapy. Clin Ther. Epub 2018 Apr 27.

9. Spallone V. Management of painful diabetic neuropathy: guideline guidance or jungle? Curr Diab Rep. 2012;12(4):403-413.

10. Pop-Busui R, Herman WH, Feldman EL, et al. DCCT and EDIC studies in type 1 diabetes: lessons for diabetic neuropathy regarding metabolic memory and natural history. Curr Diab Rep. 2010;10(4): 276-282.

11. Callaghan BC, Little AA, Feldman EL, Hughes RA. Enhanced glucose control for preventing and treating diabetic neuropathy. Cochrane Database Syst Rev. 2012;(6):Cd007543.

12. Tavakoli M, Mitu-Pretorian M, Petropoulos IN, et al. Corneal confocal microscopy detects early nerve regeneration in diabetic neuropathy after simultaneous pancreas and kidney transplantation. Diabetes. 2013;62(1):254-260.

13. Boulton AJ, Malik RA, Arezzo JC, Sosenko JM. Diabetic somatic neuropathies. Diabetes care. 2004;27(6):1458-1486.

14. Oyibo SO, Prasad YD, Jackson NJ, Jude EB, Boulton AJ. The relationship between blood glucose excursions and painful diabetic peripheral neuropathy: a pilot study. Diabet Med. 2002;19(10):870-873.

15. Javed S, Petropoulos IN, Alam U, Malik RA. Treatment of painful diabetic neuropathy. Ther Adv Chronic Dis. 2015;6(1):15-28.

16. Gore M, Dukes E, Rowbotham DJ, Tai KS, Leslie D. Clinical characteristics and pain management among patients with painful peripheral neuropathic disorders in general practice settings. Eur J Pain. 2007;11(6):652-664.

17. Handelsman Y, Bloomgarden ZT, Grunberger G, et al. American Association of Clinical Endocrinologists and American College of Endocrinology - Clinical Practice Guidelines for Developing a Diabetes Mellitus Comprehensive Care Plan - 2015-executive summary. Endocr Pract. 2015;21(4):413-437.

18. Attal N, Cruccu G, Baron R, et al. EFNS guidelines on the pharmacological treatment of neuropathic pain: 2010 revision. Eur J Neurol. 2010;17(9):e1113-e1188.
19. Bril V, England J, Franklin GM, et al. Evidence-based guideline: treatment of painful diabetic neuropathy: report of the American Academy of Neurology, the American Association of Neuromuscular and Electrodiagnostic Medicine, and the American Academy of Physical Medicine and Rehabilitation. Neurology. 2011;76(20):1758-1765.

20. Pop-Busui R, Boulton AJ, Feldman EL, et al. Diabetic neuropathy: a position statement by the American Diabetes Association. Diabetes Care. 2017;40(1):136-154.

21. NICE. Neuropathic pain in adults: pharmacological management in non-specialist settings. NICE. 2017. Available from: https://www.nice. org.uk/guidance/cg173. Accessed July 10, 2018.

22. Tesfaye S, Wilhelm S, Lledo A, et al. Duloxetine and pregabalin: high-dose monotherapy or their combination? The "COMBO-DN study" - a multinational, randomized, double-blind, parallel-group study in patients with diabetic peripheral neuropathic pain. Pain. 2013;154(12):2616-2625

23. Chong MS, Hester J. Diabetic painful neuropathy: current and future treatment options. Drugs. 2007;67(4):569-585.

24. Botney M, Fields HL. Amitriptyline potentiates morphine analgesia by a direct action on the central nervous system. Ann Neurol. 1983;13(2): $160-164$.

25. Benbouzid M, Gaveriaux-Ruff C, Yalcin I, et al. Delta-opioid receptors are critical for tricyclic antidepressant treatment of neuropathic allodynia. Biol Psychiatry. 2008;63(6):633-636.

26. de Gandarias JM, Echevarria E, Acebes I, Silio M, Casis L. Effects of imipramine administration on mu-opioid receptor immunostaining in the rat forebrain. Arzneimittelforschung. 1998;48(7):717-719.

27. Rudroju N, Bansal D, Talakokkula ST, et al. Comparative efficacy and safety of six antidepressants and anticonvulsants in painful diabetic neuropathy: a network meta-analysis. Pain Physician. 2013;16(6):E705-E714.

28. Marks DM, Shah MJ, Patkar AA, Masand PS, Park GY, Pae CU. Serotonin-norepinephrine reuptake inhibitors for pain control: premise and promise. Curr Neuropharmacol. 2009;7(4):331-336.

29. Lunn MP, Hughes RA, Wiffen PJ. Duloxetine for treating painful neuropathy, chronic pain or fibromyalgia. Cochrane Database Syst Rev. 2014;(1):CD007115.

30. Yasuda H, Hotta N, Kasuga M, et al. Efficacy and safety of $40 \mathrm{mg}$ or 60 $\mathrm{mg}$ duloxetine in Japanese adults with diabetic neuropathic pain: results from a randomized, 52-week, open-label study. J Diabetes Investig. 2016;7(1):100-108

31. Goldstein DJ, LuY, Detke MJ, Lee TC, Iyengar S. Duloxetine vs. placebo in patients with painful diabetic neuropathy. Pain. 2005;116(1-2):109-118.

32. Gao Y, Ning G, Jia WP, et al. Duloxetine versus placebo in the treatment of patients with diabetic neuropathic pain in China. Chin Med J (Engl). 2010;123(22):3184-3192

33. Kajdasz DK, Iyengar S, Desaiah D, et al. Duloxetine for the management of diabetic peripheral neuropathic pain: evidence-based findings from post hoc analysis of three multicenter, randomized, double-blind, placebocontrolled, parallel-group studies. Clin Ther. 2007;29 (Suppl):2536-2546.

34. Wernicke JF, Gahimer J, Yalcin I, Wulster-Radcliffe M, Viktrup L. Safety and adverse event profile of duloxetine. Expert Opin Drug Saf. 2005;4(6):987-993.

35. Brunton S, Wang F, Edwards SB, et al. Profile of adverse events with duloxetine treatment: a pooled analysis of placebo-controlled studies. Drug Saf. 2010;33(5):393-407.

36. Cabrera J, Emir B, Dills D, Murphy TK, Whalen E, Clair A. Characterizing and understanding body weight patterns in patients treated with pregabalin. Curr Med Res Opin. 2012;28(6):1027-1037.

37. Field MJ, Cox PJ, Stott E, et al. Identification of the alpha2-delta-1 subunit of voltage-dependent calcium channels as a molecular target for pain mediating the analgesic actions of pregabalin. Proc Natl Acad Sci. 2006;103(46):17537-17542.

38. Vinik AI, Casellini CM. Guidelines in the management of diabetic nerve pain: clinical utility of pregabalin. Diabetes Metab Syndr Obes. 2013;6:57-78. 
39. Knabl J, Witschi R, Hosl K, et al. Reversal of pathological pain through specific spinal GABAA receptor subtypes. Nature. 2008;451(7176):330-334.

40. Harrison C. Picking out the pieces of GABA receptors. Nat Rev Neurosci. 2008;9:166.

41. Barclay J, Balaguero N, Mione M, et al. Ducky mouse phenotype of epilepsy and ataxia is associated with mutations in the Cacna2d 2 gene and decreased calcium channel current in cerebellar Purkinje cells. $J$ Neurosci. 2001;21(16):6095-6104.

42. Vinik A, Rosenstock J, Sharma U, Feins K, Hsu C, Merante D; DS5565-A-U201 US Phase II Study Investigators. Efficacy and safety of mirogabalin (DS-5565) for the treatment of diabetic peripheral neuropathic pain: a randomized, double-blind, placebo- and active comparator-controlled, adaptive proof-of-concept phase 2 study. Diabetes Care. 2014;37(12):3253-3261.

43. Bravo-Hernández M, Corleto JA, Barragán-Iglesias P, et al. The $\alpha 5$ subunit-containing GABAA receptors contribute to chronic pain. Pain. 2016;157(3):613-626.

44. Lee-Kubli C, Marshall AG, Malik RA, Calcutt NA. The H-Reflex as a biomarker for spinal disinhibition in painful diabetic neuropathy. Curr Diab Rep. 2018;18(1):1.

45. Marshall AG, Lee-Kubli C, Azmi S, et al. Spinal disinhibition in experimental and clinical painful diabetic neuropathy. 2017;66(5):1380-1390

46. Chen X, Jacobs G, de Kam M, et al. The central nervous system effects of the partial GABA-A $\alpha 2,3$-selective receptor modulator AZD7325 in comparison with lorazepam in healthy males. Br J Clin Pharmacol. 2014;78(6):1298-1314.

47. Domon Y, Arakawa N, Inoue T, et al. Binding characteristics and analgesic effects of mirogabalin, a novel ligand for the $\alpha 2 \delta$ subunit of voltagegated calcium channels. J Pharmacol Exp Ther. 2018;365(3):573-582.

48. Li CY, Zhang XL, Matthews EA, et al. Calcium channel alpha2delta1 subunit mediates spinal hyperexcitability in pain modulation. Pain. 2006;125(1-2):20-34.

49. Rose MA, Kam PC. Gabapentin: pharmacology and its use in pain management. Anaesthesia. 2002;57(5):451-462.

50. Backonja M, Beydoun A, Edwards KR, et al. Gabapentin for the symptomatic treatment of painful neuropathy in patients with diabetes mellitus: a randomized controlled trial. JAMA. 1998;280(21):1831-1836.

51. Nazarbaghi S, Amiri-Nikpour MR, Eghbal AF, Valizadeh R. Comparison of the effect of topiramate versus gabapentin on neuropathic pain in patients with polyneuropathy: a randomized clinical trial. Electron Physician. 2017;9(10):5617-5622.

52. Dolgun H, Turkoglu E, Kertmen H, et al. Gabapentin versus pregabalin in relieving early post-surgical neuropathic pain in patients after lumbar disc herniation surgery: a prospective clinical trial. Neurol Res. 2014;36(12):1080-1085.

53. Serpell MG; Neuropathic Pain Study Group. Gabapentin in neuropathic pain syndromes: a randomised, double-blind, placebo-controlled trial. Pain. 2002;99(3):557-566.

54. Tai Q, Kirshblum S, Chen B, Millis S, Johnston M, DeLisa JA. Gabapentin in the treatment of neuropathic pain after spinal cord injury: a prospective, randomized, double-blind, crossover trial. $J$ Spinal Cord Med. 2002;25(2):100-105.

55. Zhang L, Rainka M, Freeman R, et al. A randomized, double-blind, placebo-controlled trial to assess the efficacy and safety of gabapentin enacarbil in subjects with neuropathic pain associated with postherpetic neuralgia (PXN110748). J Pain. 2013;14(6):590-603.

56. Brown S, Johnston B, Amaria K, et al. A randomized controlled trial of amitriptyline versus gabapentin for complex regional pain syndrome type I and neuropathic pain in children. Scand J Pain. 2016;13:156-163.

57. Gilron I, Bailey JM, Tu D, Holden RR, Jackson AC, Houlden RL. Nortriptyline and gabapentin, alone and in combination for neuropathic pain: a double-blind, randomised controlled crossover trial. Lancet. 2009;374(9697):1252-1261.

58. Mellegers MA, Furlan AD, Mailis A. Gabapentin for neuropathic pain: systematic review of controlled and uncontrolled literature. Clin J Pain. 2001;17(4):284-295.
59. Moore RA, Wiffen PJ, Derry S, Toelle T, Rice AS. Gabapentin for chronic neuropathic pain and fibromyalgia in adults. Cochrane Database Syst Rev. 2014;(4):CD007938.

60. Lesser H, Sharma U, LaMoreaux L, Poole RM. Pregabalin relieves symptoms of painful diabetic neuropathy: a randomized controlled trial Neurology. 2004;63(11):2104-2110.

61. Rosenstock J, Tuchman M, LaMoreaux L, Sharma U. Pregabalin for the treatment of painful diabetic peripheral neuropathy: a double-blind, placebo-controlled trial. Pain. 2004;110(3):628-638.

62. Richter RW, Portenoy R, Sharma U, Lamoreaux L, Bockbrader H, Knapp LE. Relief of painful diabetic peripheral neuropathy with pregabalin: a randomized, placebo-controlled trial. J Pain. 2005;6(4):253-260.

63. Arezzo JC, Rosenstock J, Lamoreaux L, Pauer L. Efficacy and safety of pregabalin $600 \mathrm{mg} / \mathrm{d}$ for treating painful diabetic peripheral neuropathy: a double-blind placebo-controlled trial. BMC Neurol. 2008;8:33.

64. Snedecor SJ, Sudharshan L, Cappelleri JC, Sadosky A, Mehta S, Botteman M. Systematic review and meta-analysis of pharmacological therapies for painful diabetic peripheral neuropathy. Pain Pract. 2014;14(2):167-184.

65. Sicras A, Rejas J, Navarro R, Planas A. Adding pregabalin or gabapentin for the management of community-treated patients with painful diabetic peripheral neuropathy: a comparative cost analysis. Clin Drug Investig. 2013;33(11):825-835.

66. Snellgrove BJ, Steinert T, Jaeger S. Pregabalin use among users of illicit drugs: a cross-sectional survey in Southern Germany. CNS Drugs. 2017;31(10):891-898.

67. Schifano F, Chiappini S, Corkery JM, Guirguis A. Abuse of prescription drugs in the context of novel psychoactive substances (NPS): a systematic review. Brain Sci. 2018;8(4):E73.

68. Wiffen PJ, Derry S, Moore RA. Lamotrigine for chronic neuropathic pain and fibromyalgia in adults. Cochrane Database Syst Rev. 2013;12:CD006044.

69. Eisenberg E, Lurie Y, Braker C, Daoud D, Ishay A. Lamotrigine reduces painful diabetic neuropathy: a randomized, controlled study. Neurology. 2001;57(3):505-509.

70. Raskin P, Donofrio PD, Rosenthal NR, et al. Topiramate vs placebo in painful diabetic neuropathy: analgesic and metabolic effects. Neurology. 2004;63(5):865-873.

71. Thienel U, Neto W, Schwabe SK, Vijapurkar U; Topiramate Diabetic Neuropathic Pain Study Group. Topiramate in painful diabetic polyneuropathy: findings from three double-blind placebo-controlled trials. Acta Neurol Scand. 2004;110(4):221-231.

72. Yin OQ, Merante D, Truitt K, Miller R. Population pharmacokinetic modeling and simulation for assessing renal impairment effect on the pharmacokinetics of mirogabalin. $J$ Clin Pharmacol. 2016;56(2):203-212.

73. Kato M, Tajima N, Shimizu T, et al. Pharmacokinetics and safety of a single oral dose of mirogabalin in Japanese subjects with varying degrees of renal impairment. J Clin Pharmacol. 2018;58(1): 57-63.

74. Jansen M, Warrington S, Dishy V, et al. A randomized, placebocontrolled, double-blind study of the safety, tolerability, pharmacokinetics, and pharmacodynamics of single and repeated doses of mirogabalin in healthy Asian volunteers. Clin Pharmacol Drug Dev. Epub 2018 Apr 17.

75. Freeman R, Durso-Decruz E, Emir B. Efficacy, safety, and tolerability of pregabalin treatment for painful diabetic peripheral neuropathy: findings from seven randomized, controlled trials across a range of doses. Diabetes Care. 2008;31(7):1448-1454.

76. Hutmacher MM, Frame B, Miller R, Truitt K, Merante D. Exposureresponse modeling of average daily pain score, and dizziness and somnolence, for mirogabalin (DS-5565) in patients with diabetic peripheral neuropathic pain. J Clin Pharmacol. 2016;56(1):67-77.

77. Moore RA, Straube S, Wiffen PJ, Derry S, McQuay HJ. Pregabalin for acute and chronic pain in adults. Cochrane Database Syst Rev. 2009;(3):CD007076. 
78. Wiffen PJ, Derry S, Bell RF, et al. Gabapentin for chronic neuropathic pain in adults. Cochrane Database Syst Rev. 2017;6:CD007938.

79. Vincent AM, Callaghan BC, Smith AL, Feldman EL. Diabetic neuropathy: cellular mechanisms as therapeutic targets. Nat Rev Neurol. 2011;7(10):573-583.

80. Brederson JD, Kym PR, Szallasi A. Targeting TRP channels for pain relief. Eur J Pharmacol. 2013;716(1-3):61-76.

81. Verheyen A, Peeraer E, Lambrechts D, et al. Therapeutic potential of VEGF and VEGF-derived peptide in peripheral neuropathies. Neuroscience. 2013;244:77-89.

82. Ropper AH, Gorson KC, Gooch CL, et al. Vascular endothelial growth factor gene transfer for diabetic polyneuropathy: a randomized, doubleblinded trial. Ann Neurol. 2009;65(4):386-393.

83. Smith MT, Wyse BD, Edwards SR. Small molecule angiotensin II type 2 receptor (AT2R) antagonists as novel analgesics for neuropathic pain: comparative pharmacokinetics, radioligand binding, and efficacy in rats. Pain Med. 2013;14(5):692-705.

84. Keppel Hesselink JM, Schatman ME. EMA401: an old antagonist of the AT2R for a new indication in neuropathic pain. J Pain Res. 2017;10: 439-443.

85. Rice AS, Dworkin RH, McCarthy TD, et al. EMA401, an orally administered highly selective angiotensin II type 2 receptor antagonist, as a novel treatment for postherpetic neuralgia: a randomised, double-blind, placebo-controlled phase 2 clinical trial. Lancet. 2014;383(9929): $1637-1647$

86. McCarthy T. Development of EMA401 as an orally-administered, highlyselective angiotensin II type 2 receptor antagonist for the treatment of neuropathic pain. J Peripher Nerv Syst. 2014;19(Suppl 2):S13-S14.

87. Blesneac I, Themistocleous AC, Fratter C, et al. Rare NaV1.7 variants associated with painful diabetic peripheral neuropathy. Pain. 2018;159(3):469-480.

88. Goldberg YP, Price N, Namdari R, et al. Treatment of Na(v)1.7-mediated pain in inherited erythromelalgia using a novel sodium channel blocker. Pain. 2012;153(1):80-85.
89. McGowan E, Hoyt SB, Li X, Lyons KA, Abbadie C. A peripherally acting $\mathrm{Na}(\mathrm{v}) 1.7$ sodium channel blocker reverses hyperalgesia and allodynia on rat models of inflammatory and neuropathic pain. Anesth Analg. 2009;109(3):951-958.

90. Xing F, Yong RJ, Kaye AD, Urman RD. Intrathecal drug delivery and spinal cord stimulation for the treatment of cancer pain. Curr Pain Headache Rep. 2018;22(2):11.

91. Deer T, Rauck RL, Kim P, et al. Effectiveness and safety of intrathecal ziconotide: interim analysis of the patient registry of intrathecal ziconotide management (PRIZM). Pain Pract. 2018;18(2):230-238.

92. Huang M, Dalm B, Simpson RK. Toxic myelitis and arachnoiditis after intrathecal delivery of bupivacaine via an implanted drug delivery system: case report and review of the literature. Cureus. 2018;10(2): e2240.

93. Swartjes M, van Velzen M, Niesters M, et al. ARA 290, a peptide derived from the tertiary structure of erythropoietin, produces long-term relief of neuropathic pain coupled with suppression of the spinal microglia response. Mol Pain. 2014;10:13.

94. Dilley A. ARA290 in a rat model of inflammatory pain. Methods Mol Biol. 2013;982:213-225.

95. Brines M, Dunne AN, van Velzen M, et al. ARA 290, a nonerythropoietic peptide engineered from erythropoietin, improves metabolic control and neuropathic symptoms in patients with type 2 diabetes. Mol Med. 2015;20:658-666

96. Heij L, Niesters M, Swartjes M, et al. Safety and efficacy of ARA 290 in sarcoidosis patients with symptoms of small fiber neuropathy: a randomized, double-blind pilot study. Mol Med. 2012;18:1430-1436.

97. Brines M, Culver DA, Ferdousi M, Tannemaat MR, van Velzen M. Corneal nerve fiber size adds utility to the diagnosis and assessment of therapeutic response in patients with small fiber neuropathy. 2018;8(1):4734.

98. Zhang W, Yu G, Zhang M. ARA 290 relieves pathophysiological pain by targeting TRPV1 channel: integration between immune system and nociception. Peptides. 2016;76:73-79.
Journal of Pain Research

\section{Publish your work in this journal}

The Journal of Pain Research is an international, peer reviewed, open access, online journal that welcomes laboratory and clinical findings in the fields of pain research and the prevention and management of pain. Original research, reviews, symposium reports, hypothesis formation and commentaries are all considered for publication.

\section{Dovepress}

The manuscript management system is completely online and includes a very quick and fair peer-review system, which is all easy to use. Visit http://www.dovepress.com/testimonials.php to read real quotes from published authors. 